\title{
25 Research Soure \\ On the Role of Atmospheric Simulations Horizontal Grid Spacing for Flood Modeling
}

Felipe Quintero ( $\square$ felipe-quintero@uiowa.edu )

The University of lowa IIHR Hydroscience and Engineering https://orcid.org/0000-0001-9517-4895

\section{Gabriele Villarini}

The University of lowa IIHR Hydroscience and Engineering

Andreas F. Prein

NCAR: National Center for Atmospheric Research

\section{Witold F. Krajewski}

The University of lowa IIHR Hydroscience and Engineering

Wei Zhang

Utah State University

\section{Research Article}

Keywords: Precipitation, Resolution, Hydrology, Peak Flows

Posted Date: August 24th, 2021

DOl: https://doi.org/10.21203/rs.3.rs-821389/v1

License: (c) (1) This work is licensed under a Creative Commons Attribution 4.0 International License. Read Full License 


\section{Abstract}

Our study focuses on the hydrologic implications of resolving and modeling atmospheric processes at different spatial scales. Here we use heavy precipitation events from an atmospheric model that was run at different horizontal grid spacings (i.e., $250 \mathrm{~m}, 500 \mathrm{~m}, 1 \mathrm{~km}, 2 \mathrm{~km} 4 \mathrm{~km}$, and $12 \mathrm{~km}$ ) and able to resolve different processes. Within an idealized simulation framework, these rainfall events are used as input to an operational distributed hydrologic model to evaluate the sensitivity of the hydrologic response to different forcing grid spacings. We consider the finest scale (i.e., $250 \mathrm{~m}$ ) as reference, and compute event peak flows and volumes across a wide range of basin sizes. We find that the use of increasingly-coarser inputs leads to changes in the distribution of event peak flows and volumes, with the strongest sensitivity at the smallest catchment sizes. Overall, we find that $4-\mathrm{km}$ rainfall simulations represent a good compromise between computational costs and hydrologic performance, providing basic information for future endeavors geared towards regional downscaling.

\section{Introduction}

Precipitation is the main driver used by hydrologic models to simulate the response of the river basins during flood events. Without an adequate representation of precipitation it is expected that the hydrologic response is biased, leading to an overestimation or underestimation of discharge (Fang and Pomeroy 2016; Bennett et al. 2018; Berghuijs et al. 2019; Grimley et al. 2020). Although these biases can be caused by other components of the hydrologic modeling, precipitation has a very important role (e.g. Quintero et al. 2012; Ayalew et al. 2014). It is also intuitive that the hydrologic models are sensitive to the level of detail used by atmospheric models to describe the physics of precipitation: it is expected that the higher the spatial and temporal resolution of precipitation, the better the representation of this phenomenon, resulting in higher expected accuracy of the hydrologic models.

The role of precipitation horizontal resolution from numerical models in hydrologic predictions has been explored in the literature (e.g. Graham et al. 2007; Dankers et al. 2007; van Roosmalen et al. 2010; Rasmussen et al. 2011; Prein et al. 2013; Olsson et al. 2015; Mendoza et al. 2016) showing mixed conclusions. There is agreement that the use of kilometer-scale horizontal grids or finer allows for better simulation of heavy summer events, compared to using coarser (36 to 50-km) resolutions. Rasmussen et al. (2014) reported that the use of 12 - and $36-\mathrm{km}$ resolutions results in the underestimation of basinaveraged annual precipitation totals with respect to $4-\mathrm{km}$ precipitation simulations. In terms of the hydrologic signatures, Mendoza et al. (2016) found that precipitation horizontal resolution has a tremendous effect on the basin water balance at the annual scale (i.e., variations in mean annual runoff and evapotranspiration), regardless of the hydrologic model structure selected.

Simulating precipitation with high spatial and temporal resolution has received extensive attention in the literature, with its realism that has been increasing due to the increased computational resources and the better representation of the processes at play. In particular, the advent of convection-permitting (i.e., kilometer-scale) modeling capabilities that allow to turn off error-prone deep convection 
parameterizations and largely improve land atmosphere interactions (e.g., orographic precipitation processes) has led to a step improvement in simulating heavy precipitation events in weather (e.g., Clark et al. 2016) and climate (Prein et al. 2015, 2021; Fowler et al. 2021) applications. However, kilometerscale models are unable to resolve turbulent atmospheric motions properly and largely underestimate entrainment of mid-level air into convective storms resulting in an overestimation of vertical wind speeds and peak precipitation rates (Bryan and Morrison 2012; Prein et al. 2015; Wang et al. 2020; Kendon et al. 2021). Large-eddy simulations (LES) with grid spacings of equal or less than $250 \mathrm{~m}$ are necessary to improve the simulation of turbulent mixing of deep convective clouds (Lebo and Morrison 2015). The consequences of these deficiencies in kilometer-scale models on hydrologic applications are largely unknown so far.

Having a high-resolution input is important as long as we have a hydrologic model that is able to take advantage of it, making the use of distributed hydrologic models critical. Differently from lumped models, distributed models decompose the landscape into small units, and route the flow across the river network to estimate discharge. A more detailed description of the river network allows providing insights at the smaller basin scales, where it is very important to understand the expected hydrologic response. A finer decomposition of the river network allows also making better use of the detailed precipitation input, mitigating errors related to the aggregation of forcing across large-basin scales.

While we would like to simulate precipitation at turbulence-resolving (i.e., LES) scales and with the most realistic physics, this is currently not possible because of the prohibitive computational costs. However, it is unclear how large the errors from using kilometer-scale atmospheric model outputs are in terms of event flood peaks and volumes. Here, we take advantage of a unique dataset (Prein et al. 2021) that allows us to explore the sensitivity of hydrologic simulations to different rainfall resolutions and the associated physical processes across different catchment sizes.

\section{Materials And Methods}

We use a ten-member ensemble of idealized Mesoscale Convective System (MCS) simulations performed with the Weather Research and Forecasting (WRF) model v. 3.9.1.1 (Skamarock and Klemp 2008; Powers et al. 2017) presented in Prein et al. (2021). The simulations are initialized with intense precipitation producing pre-MCS soundings from the central U.S. and develop realistic mesoscale organization and precipitation rates. Each event is run for seven hours over a $600 \mathrm{~km} \times 600 \mathrm{~km}$ domain, and the model output is saved every five minutes. A unique aspect of this ensemble is that each event is simulated at various grid spacings including 12-km, 4-km, 2-km, 1-km, 500-m, and 250-m while the other model settings stayed largely unchanged (except for the model time step and the use of a deep-convection scheme in the 12-km simulations). This allows a systematic assessment of the impact of atmospheric model grid spacing on event flood peaks and volumes. For more information on these simulations, see Prein et al. (2021). 
We overlayed the precipitation domain on top of the area containing the river network of the state of lowa. The location of the precipitation cells and their movement is different from event to event, and falls over different areas of the river network. To maximize the number of basins that receive precipitation, we also rotated the precipitation fields by 90,180 and 270 degrees. This results in expanding our dataset from 10 to 40 synthetic events.

For the hydrologic simulations we used the Hillslope Link Model (HLM) (Quintero et al. 2020), a continuous distributed hydrologic model that uses hillslopes and channel links as the primary units for landscape decomposition where the hydrologic processes are modeled. We used a simplified version of the model where the transformation of precipitation into runoff is controlled by a runoff coefficient equal to one; that is, all the precipitation is converted into surface runoff and eventually into discharge in the channel. Routing is modeled using a non-linear representation of water velocity that considers the geomorphologic characteristics of the channels (Mantilla 2005; Ghimire 2018). Hillslopes and channels are obtained from a 90-meter DEM; the average area of the hillslopes is $0.1 \mathrm{~km}^{2}$ and the average channel length is $600 \mathrm{~m}$ (Quintero and Krajewski 2018). This partitioning allows the characterization of the streamflow predictions at a wide range of spatial scales, ranging from tenths to thousands of square kilometers.

We created lookup tables that relate the rainfall grids and the polygons describing the hillslopes. The lookup table allows obtaining the rainfall rate at each hillslope, as a weighted sum of the cells intersecting the hillslope that considers the intersection area. The hydrologic model was forced with a total of $10 \times 4 \times 6=240$ inputs, that result from the original 10 rainfall events, rotated in 4 directions, and at 6 different spatial resolutions. The seven hours of rainfall were forced into the model, and then the water routed for 15 days to allow all the runoff to leave the domain.

For every model simulation we obtained the peak flow and total volume at every channel link of the river network where Horton-Strahler order is equal or larger than 4, resulting in 50,000 channels, representing basin between 10 and $100,000 \mathrm{~km}^{2}$. We used the simulations that were forced with inputs at $250 \mathrm{~m}$ gridcell size as reference, and obtained the relative differences (in percentage) of peak flows and volumes at every river network channel using the equation:

$$
e_{i, j}=\left(\frac{x_{i, j}-x_{i, 250}}{x_{i, 250}}\right) \times 100
$$

where $i$ is the channel link, $j$ is the resolution of the precipitation modeling and ranges from $500 \mathrm{~m}$ to 12 $\mathrm{km}$, and $\mathrm{x}$ is the analyzed variable, either simulated peak flow $\left(\mathrm{m}^{3} \mathrm{~s}^{-1}\right)$ or total volume $\left(\mathrm{m}^{3}\right)$. The characterization of the relative differences allowed us to analyze the effect of decreased precipitation resolution in peak flows and volumes, as a function of basin size.

\section{Results}


We illustrate the methodology by selecting one precipitation event and one basin in Figure 1. The upper panel in Figure 1 shows the total precipitation for one of the events for the six horizontal resolutions. Not only do the precipitation values change across resolutions, but also the location of the highest precipitation values (e.g., compare the 12-km resolution with the other ones). This is because we are not simply coarsening the highest resolution, but because of the limited predictability and chaotic behavior of convection and the accuracy of the explicitly simulated physical processes in those simulations (e.g., turbulent motions), leading to different simulated rainfall (Prein et al. 2021). When we force the hydrologic model with the various inputs, we obtain different hydrologic responses (Figure 2, bottom panel). The simulation driven by the highest-resolution input shows a first peak during Day 2 , followed by a second and smaller peak during Day 3. As we consider coarser resolutions, this pattern is generally captured by the simulations at $500 \mathrm{~m}$ and $1 \mathrm{~km}$. At the $2-\mathrm{km}$ scale, the hydrograph is smoother and the first and second peaks are of comparable magnitude; the 4-km simulation, on the other hand, has a single peak that is about $25 \%$ larger than the reference simulation; finally, the $12-\mathrm{km}$ results show a response in which the second peak is much larger than the first one. The upper panel in Figure 2 shows the mean areal rainfall of the different precipitation inputs. The changes in volume and temporal distribution of the basin precipitation explain the differences of the hydrologic simulations, which are more visible for the simulations with larger grid spacing.

The results in Figure 1 and 2 are representative of one event and one basin. In Figure 3, we expand the analyses across the entire domain, all the storms and their rotations, and by stratifying the results by catchment size (i.e., from basins smaller than $100 \mathrm{~km}^{2}$ to basins larger than $10,000 \mathrm{~km}^{2}$ ). Each boxplot shows the distribution of absolute errors in terms of runoff, when forcing the model with inputs from coarser horizontal grid spacing simulations ( $500 \mathrm{~m}$ to $12 \mathrm{~km}$ ), compared to the corresponding simulation using $250 \mathrm{~m}$ inputs. The behavior of the differences is similar for the peak flows and the volumes: as the horizontal grid spacing of precipitation increases, the range of variability of the errors increases as well. If we use the median as point estimate, we see that the errors for grid spacing between $500 \mathrm{~m}$ and $2 \mathrm{~km}$ are close to zero, with an underestimation of the peaks and volumes for larger grid spacing. This behavior is particularly evident for the smaller basins, while the dependence on the input grid spacing tends to decrease at increasing basin sizes for peak flows, and to increase for volumes.

We also explored the effect of precipitation intensity in the results. Figures 4 and 5 show quantile-quantile plots of the peak flows and total volumes obtained with the simulations, grouped by basin drainage area. We observe that the bigger differences are obtained for the larger values of peak flow and larger volumes (the values in the right tail of the distribution), and for all the basin sizes. In the case of peak flows (Figure 4), the larger differences are not necessarily always obtained with the coarser grid spacing input; for instance, in basins between 100 and $1000 \mathrm{~km}^{2}$ the largest differences are obtained with the $1-\mathrm{km}$ output, and in the groups of basins larger than $1000 \mathrm{~km}^{2}$ the largest differences are obtained with the 4-km grid output. In the case of total volume (Figure 5) there seem to be a clearer linear dependence between the grid spacing and the differences; the largest differences across all the quantiles of the distribution are obtained with the 12-km grid spacing output, across all the basin sizes. Our model configuration 
guarantees that all the precipitation becomes runoff and does not get stored in the soil; therefore, the results are not affected by water loss in the runoff generation process. The results can be explained by the errors in the position of the storm cells with respect to the river network, errors in the spatial pattern of precipitation, and errors in the input precipitation intensity. Using coarser grid spacing input can result in overlaying precipitation on top of basins that, according to the benchmark input, should not have receive any precipitation; if the displacement is small, the water eventually drains out at the larger scale basin outlets, which explains why volume errors in large basin sizes are smaller. The displacement of precipitation also attenuates the peak flows because, even if the same volume of water is routed along the river network, the aggregation of the flow occurs with a different velocity and timing compared to the benchmark. It is important to mention that the displacement of precipitation is mainly due to small-scale convective processes because the overall storm movements are very similar across grid-spacings (the storm tracks agree within 10 km between 250-m and 4-km simulations) except for the 12-km simulations (see Figure $3 \mathrm{~h}$ in Prein et al. (2021)).

\section{Conclusions And Recommendations}

We designed an experiment that provides insights about how the horizontal grid-spacing of atmospheric models and their correspondent representation of precipitation can influence the outcomes of hydrologic simulations at event temporal scales. We took advantage of a unique precipitation dataset that allowed us to explore the impact of atmospheric model resolutions ranging from $250 \mathrm{~m}$ to $12 \mathrm{~km}$. We showed that coarser-resolution models lead to an overall underestimation in the distribution of peak flows and volumes. These differences are particular evident for smaller basins and become smaller for larger catchments.

There is a loss of fidelity in reproducing rainfall processes as we coarsen the atmospheric model resolutions. However, it is currently not feasible to perform extensive simulations for long periods and across a large domain at a resolution of $250 \mathrm{~m}$ because computational costs are approximately ten-fold when doubling the model grid spacing. While we would not recommend a 12-km resolution because of the errors associated with these simulations, we suggest a 4-km resolution as a reasonable compromise between accuracy and computational costs. This suggestion is a compromise between simulation accuracy and computing power (i.e., our ability to run large-ensembles or long periods) and would be revisited considering future computational advances.

\section{Declarations}

Acknowledgements: This work was supported in part by the lowa Department of Transportation (Project number 20-SPR2-002). The opinions, findings, and conclusions expressed in this publication are those of the author and not necessarily those of the lowa Department of Transportation or the United States Department of Transportation, Federal Highway Administration. Support by the lowa Flood Center, IIHRHydroscience \& Engineering, and the U.S. Army Corps of Engineers' Institute for Water Resources is 
gratefully acknowledged. NCAR is partly funded by the National Science Foundation under Cooperative Agreement No. 1852977.

Funding: This work was supported in part by the lowa Department of Transportation (Project number 20SPR2-002). NCAR is partly funded by the National Science Foundation under Cooperative Agreement No. 1852977.

Conflicts of interest/Competing interests: Nothing to declare.

Availability of data and material: The hydrologic simulations that support the findings of this study are available from the corresponding author upon reasonable request.

Code availability: Custom codes that support the statistical modeling results are available from the corresponding author upon request.

Authors' contributions: FQ, GV, and AP designed the experiments; FQ and AP performed the analyses. All authors interpreted the results and wrote the paper.

Additional declarations for articles in life science journals that report the results of studies involving humans and/or animals: Not applicable' for that section.

Ethics approval: Nothing to declare

Consent to participate: Nothing to declare.

Consent for publication: Nothing to declare.

\section{References}

Ayalew TB, Krajewski WF, Mantilla R, Small SJ (2014) Exploring the effects of hillslope-channel link dynamics and excess rainfall properties on the scaling structure of peak-discharge. Adv Water Resour 64:9-20. https://doi.org/10.1016/j.advwatres.2013.11.010

Bennett B, Leonard M, Deng Y, Westra S (2018) An empirical investigation into the effect of antecedent precipitation on flood volume. J Hydrol 567:435-445. https://doi.org/10.1016/j.jhydrol.2018.10.025

Berghuijs WR, Harrigan S, Molnar P, et al (2019) The Relative Importance of Different Flood-Generating Mechanisms Across Europe. Wiley Online Libr 55:4582-4593. https://doi.org/10.1029/2019WR024841

Bryan GH, Morrison H (2012) Sensitivity of a simulated squall line to horizontal resolution and parameterization of microphysics. Mon Weather Rev 140:202-225. https://doi.org/10.1175/MWR-D-1100046.1

Clark P, Roberts N, Lean H, et al (2016) Convection-permitting models: A step-change in rainfall forecasting. Meteorol. Appl. 23:165-181 
Dankers R, Christensen OB, Feyen L, et al (2007) Evaluation of very high-resolution climate model data for simulating flood hazards in the Upper Danube Basin. J Hydrol 347:319-331.

https://doi.org/10.1016/j.jhydrol.2007.09.055

Fang X, Pomeroy JW (2016) Impact of antecedent conditions on simulations of a flood in a mountain headwater basin. Wiley Online Libr 30:2754-2772. https://doi.org/10.1002/hyp.10910

Fowler HJ, Lenderink G, Prein AF, et al (2021) Anthropogenic intensification of short-duration rainfall extremes. Nat Rev Earth Environ. https://doi.org/10.1038/s43017-020-00128-6

Graham LP, Andreáasson J, Carlsson B (2007) Assessing climate change impacts on hydrology from an ensemble of regional climate models, model scales and linking methods - A case study on the Lule River basin. Clim Change 81:293-307. https://doi.org/10.1007/s10584-006-9215-2

Grimley LE, Quintero F, Krajewski WF (2020) Streamflow predictions in a small urban-rural watershed: The effects of radar rainfall resolution and urban rainfall-runoff dynamics. Atmosphere (Basel) 11:774. https://doi.org/10.3390/ATMOS11080774

Kendon EJ, Prein AF, Senior CA, Stirling A (2021) Challenges and outlook for convection-permitting climate modelling. Philos. Trans. R. Soc. A Math. Phys. Eng. Sci. 379

Lebo ZJ, Morrison H (2015) Effects of horizontal and vertical grid spacing on mixing in simulated squall lines and implications for convective strength and structure. Mon Weather Rev 143:4355-4375. https://doi.org/10.1175/MWR-D-15-0154.1

Mendoza PA, Mizukami N, Ikeda K, et al (2016) Effects of different regional climate model resolution and forcing scales on projected hydrologic changes. J Hydrol 541:1003-1019.

https://doi.org/10.1016/j.jhydrol.2016.08.010

Olsson J, Berg P, Kawamura A (2015) Impact of RCM spatial resolution on the reproduction of local, subdaily precipitation. J Hydrometeorol 16:534-547. https://doi.org/10.1175/JHM-D-14-0007.1

Powers JG, Klemp JB, Skamarock WC, et al (2017) The weather research and forecasting model: Overview, system efforts, and future directions. Bull Am Meteorol Soc 98:1717-1737. https://doi.org/10.1175/BAMS-D-15-00308.1

Prein AF, Holland GJ, Rasmussen RM, et al (2013) Importance of regional climate model grid spacing for the simulation of heavy precipitation in the colorado headwaters. J Clim 26:4848-4857. https://doi.org/10.1175/JCLI-D-12-00727.1

Prein AF, Langhans W, Fosser G, et al (2015) A review on regional convection-permitting climate modeling: Demonstrations, prospects, and challenges. Rev. Geophys. 53:323-361 
Prein AF, Rasmussen RM, Wang D, Giangrande SE (2021) Sensitivity of organized convective storms to model grid spacing in current and future climates. Philos Trans R Soc A Math Phys Eng Sci 379:. https://doi.org/10.1098/rsta.2019.0546

Quintero F, Krajewski WF (2018) Mapping Outlets of lowa Flood Center and National Water Center River Networks for Hydrologic Model Comparison. J Am Water Resour Assoc 54:28-39.

https://doi.org/10.1111/1752-1688.12554

Quintero F, Krajewski WF, Seo BC, Mantilla R (2020) Improvement and evaluation of the lowa Flood Center Hillslope Link Model (HLM) by calibration-free approach. J Hydrol 584:.

https://doi.org/10.1016/j.jhydrol.2020.124686

Quintero F, Sempere-Torres D, Berenguer M, Baltas E (2012) A scenario-incorporating analysis of the propagation of uncertainty to flash flood simulations. J Hydrol 460-461:90-102.

https://doi.org/10.1016/j.jhydrol.2012.06.045

Rasmussen R, lkeda K, Liu C, et al (2014) Climate change impacts on the water balance of the Colorado headwaters: High-resolution regional climate model simulations. J Hydrometeorol 15:1091-1116. https://doi.org/10.1175/JHM-D-13-0118.1

Rasmussen R, Liu C, Ikeda K, et al (2011) High-resolution coupled climate runoff simulations of seasonal snowfall over Colorado: A process study of current and warmer climate. J Clim 24:3015-3048. https://doi.org/10.1175/2010JCLI3985.1

Skamarock WC, Klemp JB (2008) A time-split nonhydrostatic atmospheric model for weather research and forecasting applications. J Comput Phys 227:3465-3485. https://doi.org/10.1016/j.jcp.2007.01.037

van Roosmalen L, Christensen JH, Butts MB, et al (2010) An intercomparison of regional climate model data for hydrological impact studies in Denmark. J Hydrol 380:406-419.

https://doi.org/10.1016/j.jhydrol.2009.11.014

Wang D, Giangrande SE, Feng Z, et al (2020) Updraft and Downdraft Core Size and Intensity as Revealed by Radar Wind Profilers: MCS Observations and Idealized Model Comparisons. J Geophys Res Atmos 125:e2019JD031774. https://doi.org/10.1029/2019JD031774

\section{Figures}



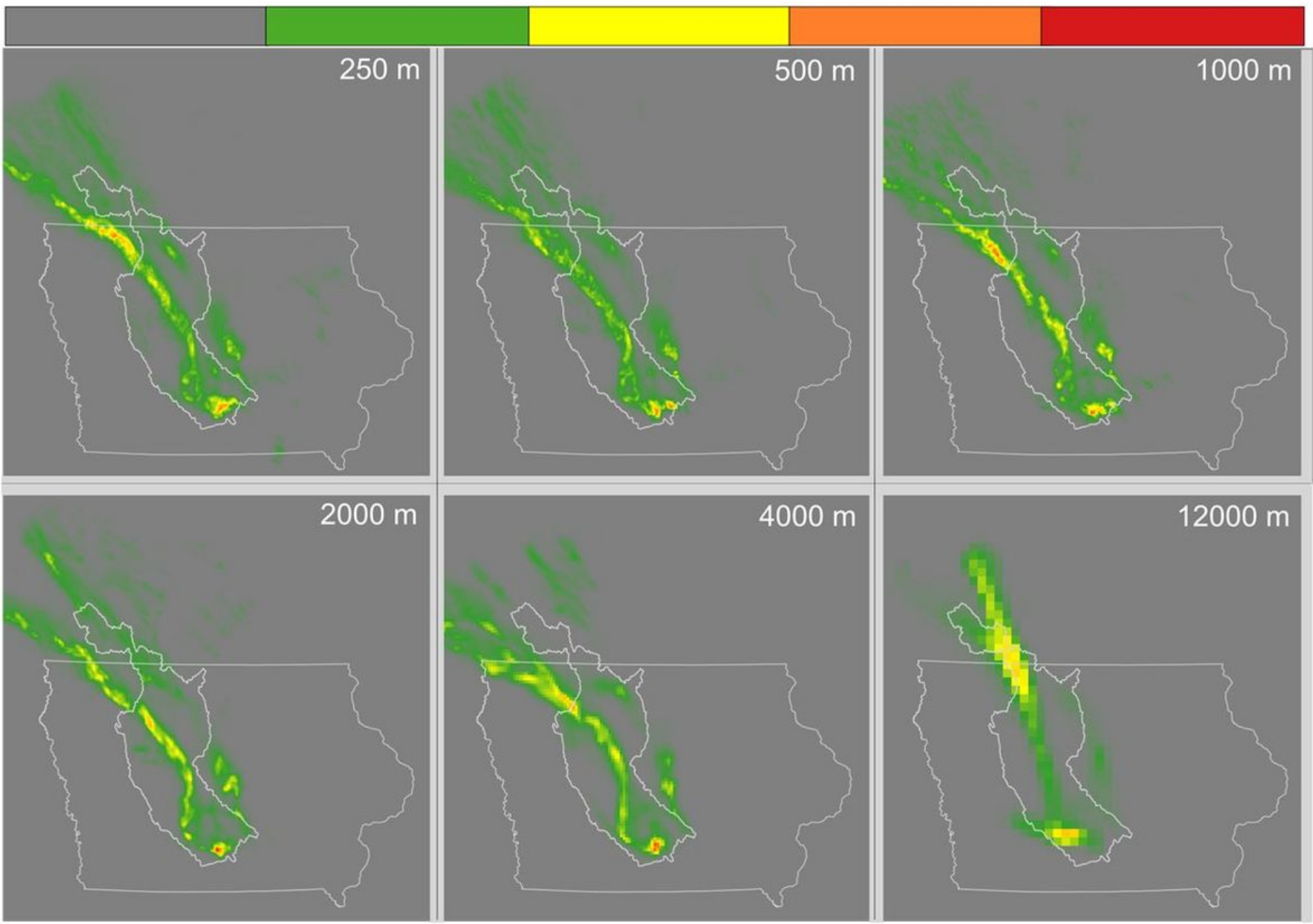

\section{Figure 1}

Total rainfall accumulation of one rainfall events used in the experiment, after modeling precipitation at six horizontal grid spacings varying from $250 \mathrm{~m}$ (top-left map) to $12 \mathrm{~km}$ (bottom-right map). The large polygon shows the boundaries of the state of lowa, and the small polygon the catchment delineation of the Des Moines river basin near Tracy. 

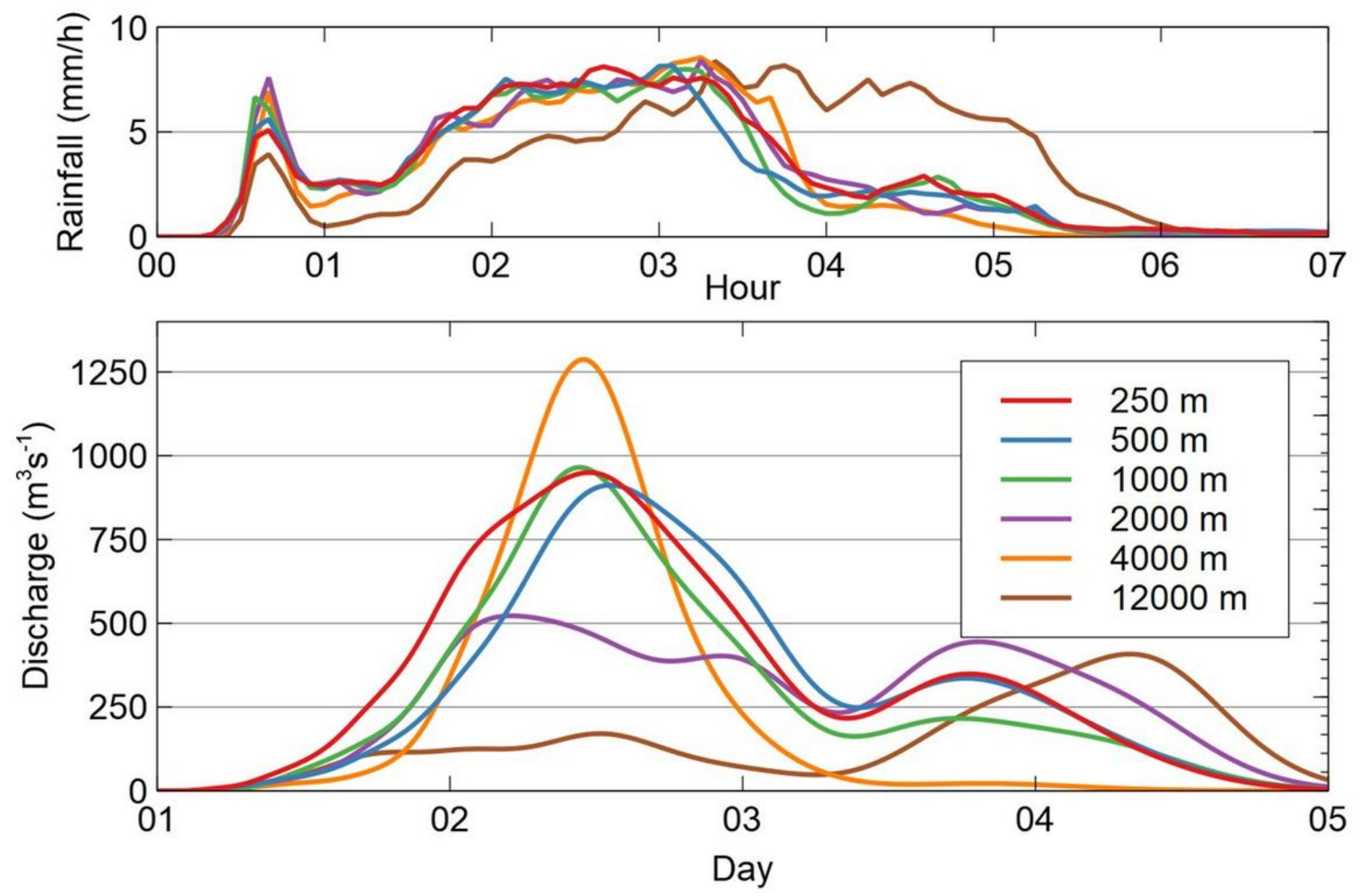

Figure 2

The upper panel shows the mean areal rainfall for each precipitation input. The bottom panel shows the hydrologic response of the basin to the six precipitation inputs. 

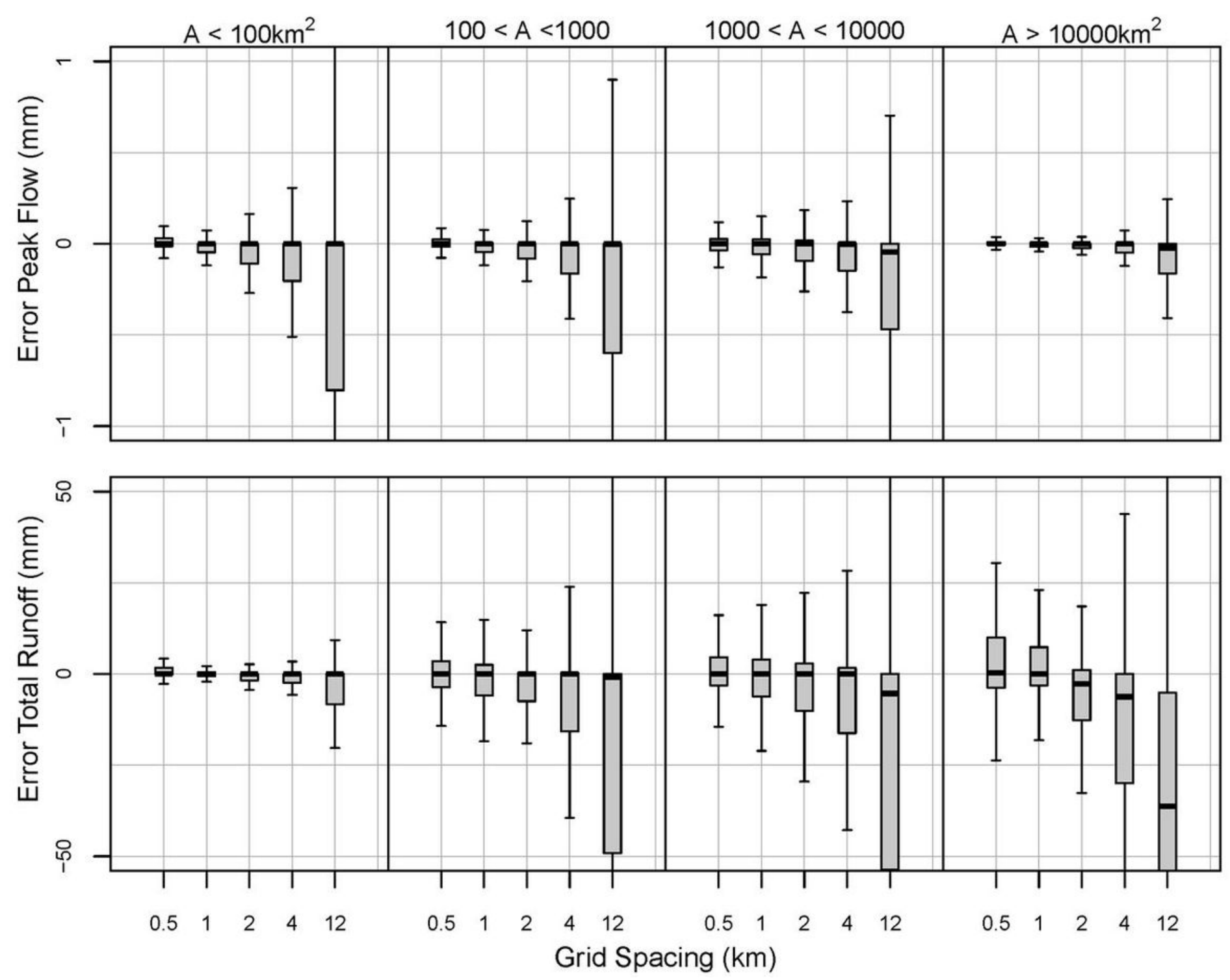

Figure 3

The upper (lower) row shows the distribution of peak flow (total volume) absolute error after forcing the model with precipitation inputs of different horizontal grid spacing, compared to the reference provided by the $250-\mathrm{m}$ precipitation input. The analysis is conditioned by the size of the basin where the differences were obtained. 


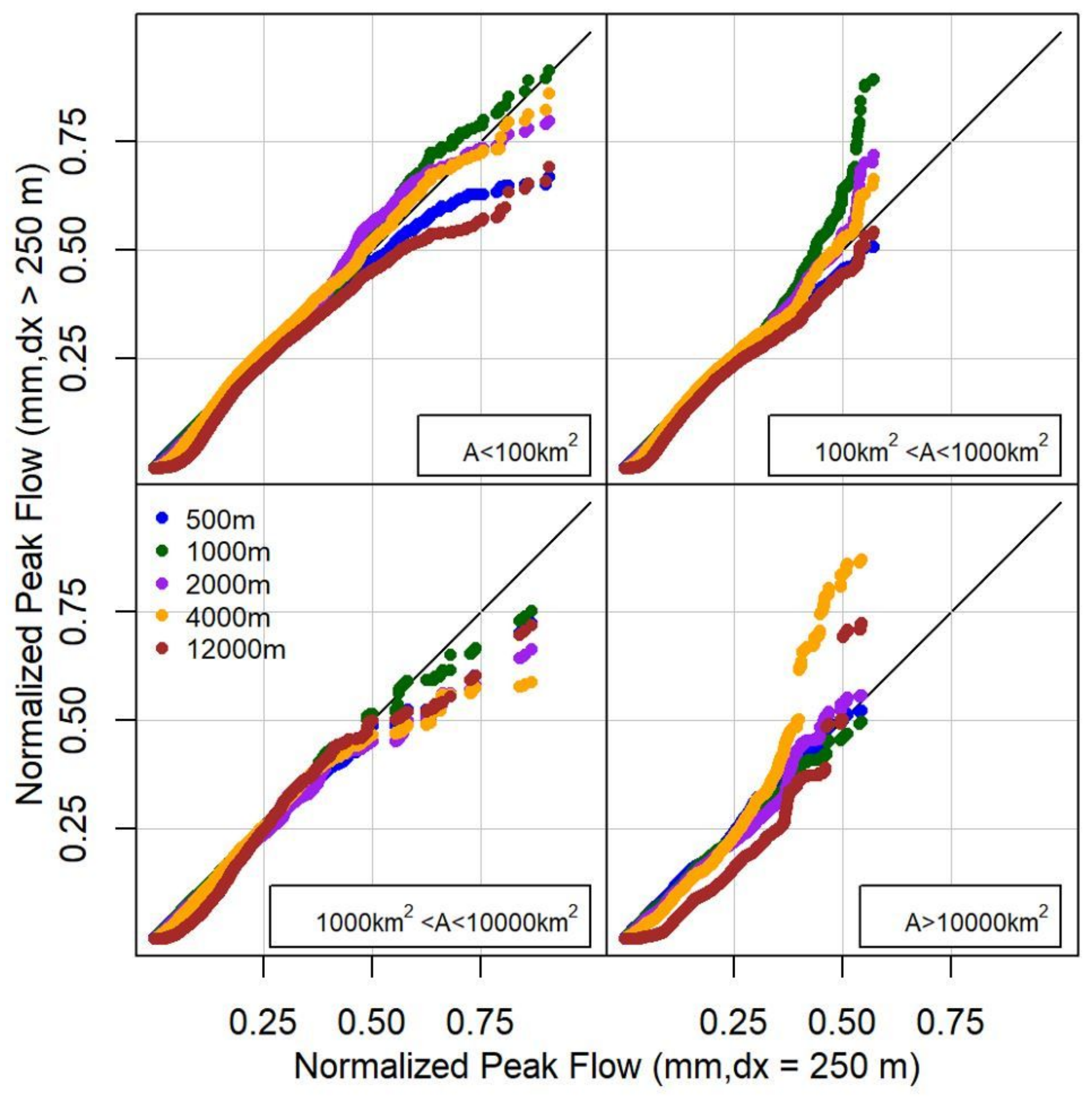

Figure 4

Quantile-quantile plots comparing the distribution of peak flows. The x-axis shows the normalized peak flow quantiles of the reference product $(250 \mathrm{~m})$. The $y$-axis shows the normalized peak flow quantiles for grid spacing larger than $250 \mathrm{~m}$. 


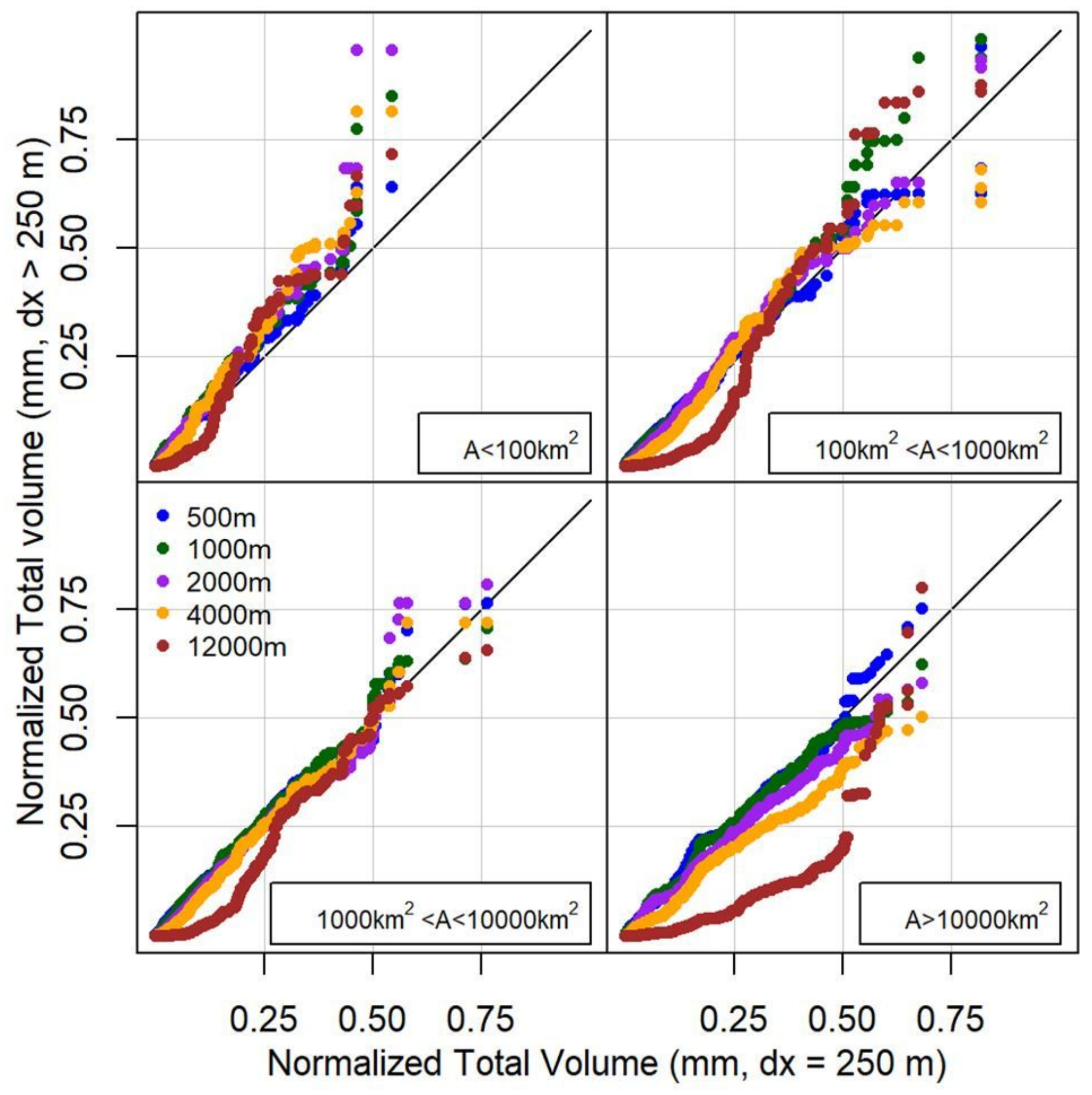

Figure 5

Quantile-quantile plots comparing the distribution of total volume. The x-axis shows the normalized totalvolume quantiles of the reference product $(250 \mathrm{~m})$. The $y$-axis shows the normalized total-volume quantiles for grid spacing larger than $250 \mathrm{~m}$. 